\title{
IDENTIFICAÇÃO DOS MINERAIS DO GRANITO AZUL SUCURU ATRAVÉS DA TÉCNICA DA DIFRAÇÂO DE RAIOS X
}

\author{
L. F. M. CAVAlCANTI ${ }^{*}$, F. M. C. Oliveira, E. B. MElO e A. C. FERnANDES \\ Universidade Federal de Pernambuco - UFPE \\ flaviomat2004@hotmail.com*
}

Artigo submetido em abril/2016 e aceito em setembro/2016

DOI: $10.15628 /$ holos. 2016.4450

\section{RESUMO}

A técnica de difração de raios $X$ (DRX) tem sido amplamente utilizada para a determinação de fases cristalinas em rochas com finalidades ornamentais e/ou aplicação como insumos da construção civil, propiciando a investigação de pequeníssimas estruturas da matéria. Partindo desse principio, o método de DRX permite caracterizar um ou mais minerais presentes na rocha. A caracterização mineralógica descreve quais minerais estão presentes na amostra, feita por meio da comparação de seus difratogramas com padrões de referência, disponíveis em bancos de dados de DRX, observando os picos mais intensos de cada composto cristalino presente no banco de dados e comparando aos picos dos difratogramas da amostra, para então serem observados os principais minerais existentes na rocha. Essa pesquisa busca mostrar os minerais presentes na estrutura desse material para então analisar possíveis aplicações industriais desse material. É apresentado neste trabalho um
\end{abstract}

método simples e confiável para a determinação de características gerais do granito Azul Sucuru através da técnica de difração de raios- $X$, para observar a presença de minerais ferro-magnesianos em sua estrutura, estando sujeitos a susceptibilidade a processos de oxidação, potencializados em atmosferas úmidas. Logo, a partir da DRX possibilita a identificação dos minerais principais (ao passo que a microscopia não foi capaz de identificar alguns minerais, mas sim seus grupos), sendo esse um método que pode ser considerados complementar para a caracterização mineralógica de rochas. A partir dos resultados obtidos pretende-se verificar a existência da cordierita nesse material, a qual potencializa a cor azul da rocha analisada, além dos minerais presentes no pó da brita desse material, proporcionando uma possível aplicação na indústria da construção civil e como rocha ornamental e de revestimento.

PALAVRAS-CHAVE: difração de raios $\mathrm{X}$, granito sucuru; quartzo; cordierita.

\section{ENVIRONMENTAL REFUGEES: CLIMATE CHANGE AND INTERNATIONAL LIABILITY}

\section{ABSTRACT}

The technique of X-ray diffraction (XRD) has been widely used for the determination of crystalline phases in rocks with ornamental purposes and / or application as construction inputs, allowing the investigation of tiny structures of matter. Based on this principle, the XRD method to characterize one or more minerals in the rock. The mineralogical characterization describes what minerals are present in the sample, made by comparing their diffraction patterns with reference standards available in DRX databases, noting the most intense peaks of each crystalline compound present in the database and comparing the peaks the XRD patterns of the sample to be observed then the main existing in rock minerals. This research aims to show the minerals present in the structure of the material and then analyze possible industrial applications of this material. This study describes an easy
\end{abstract}

and reliable method for determining overall characteristics of granite Blue Sucuru through the technique of diffraction $X$-rays to observe the presence of mineral ironmagnesian in its structure, being subject to susceptibility to oxidation processes, potentiated in humid atmospheres. Therefore, from the DRX allows the identification of the major minerals (whereas microscopy has not been able to identify certain minerals, but their groups), this being a method that can be considered complementary to the mineralogical characterization of rocks. From the results obtained it is intended to verify the existence of cordierite this material, which enhances the blue color of the examined rock, besides the minerals present in the gravel of the material powder, providing a possible application in the construction industry and as an ornamental rock and coating.

KEYWORDS: X-ray diffraction, sucuru granite; quartz; cordierite. 


\section{INTRODUÇÃO}

Segundo a ABIROCHAS (2001), as rochas ornamentais e de revestimento, também designadas pedras naturais, rochas lapídeas, rochas dimensionais e materiais de cantaria, abrangem os tipos litológicos que podem ser extraídos em blocos ou placas, cortados em formas variadas e beneficiados através de esquadrejamento, polimento, lustro, etc. O Brasil está entre os cinco maiores produtores de rochas ornamentais do mundo. Entretanto características intrínsecas dessas rochas devem ser analisadas e avaliadas para verificação de possíveis aplicações no mercado produtor. Assim, a caracterização mineralógica do "Granito Azul Sucuru" utiliza a técnica de difração de raios-X para fazer uma análise qualitativa dos minerais presentes na amostra britada do material extraído e sugerir possíveis aplicações do mesmo na construção civil, seja como material de revestimento e/ou como agregados na forma de brita ou fração areia na produção de argamassas.

\section{FUNDAMENTAÇÃO TEÓRICA}

\subsection{Geologia Regional e Local}

Segundo o Programa de Levantamentos Geológicos Básicos do Brasil, CPRM (1998), a região objeto deste projeto de lavra está posicionada no interior de uma unidade geotectônica, denominada de Terreno Alto Moxotó e, mais especificamente, por litologias do Complexo Sumé, constituídas por gnaisses, ortognaisses e migmatitos, calcários metamórficos, faixas de anfibolitos, ortognaisses e migmatitos e rochas plutônicas granulares, na forma de stocks, com pouca ou nenhuma expressão topográfica e rochas graníticas filonianas.

Neste contexto ocorrem estruturas rochosas, na forma de diques intrusivos, póstectônicos, discordantes, deformados e encaixados em rochas migmatíticas e gnáissicas do embasamento pré-cambriano, sob a forma de diques verticalizados a subverticalizados, orientados na direção N-S, constituídos por amontoados de matacões, posicionados sobre os diques ou parcialmente deslocados, observado na figura 1, a seguir:

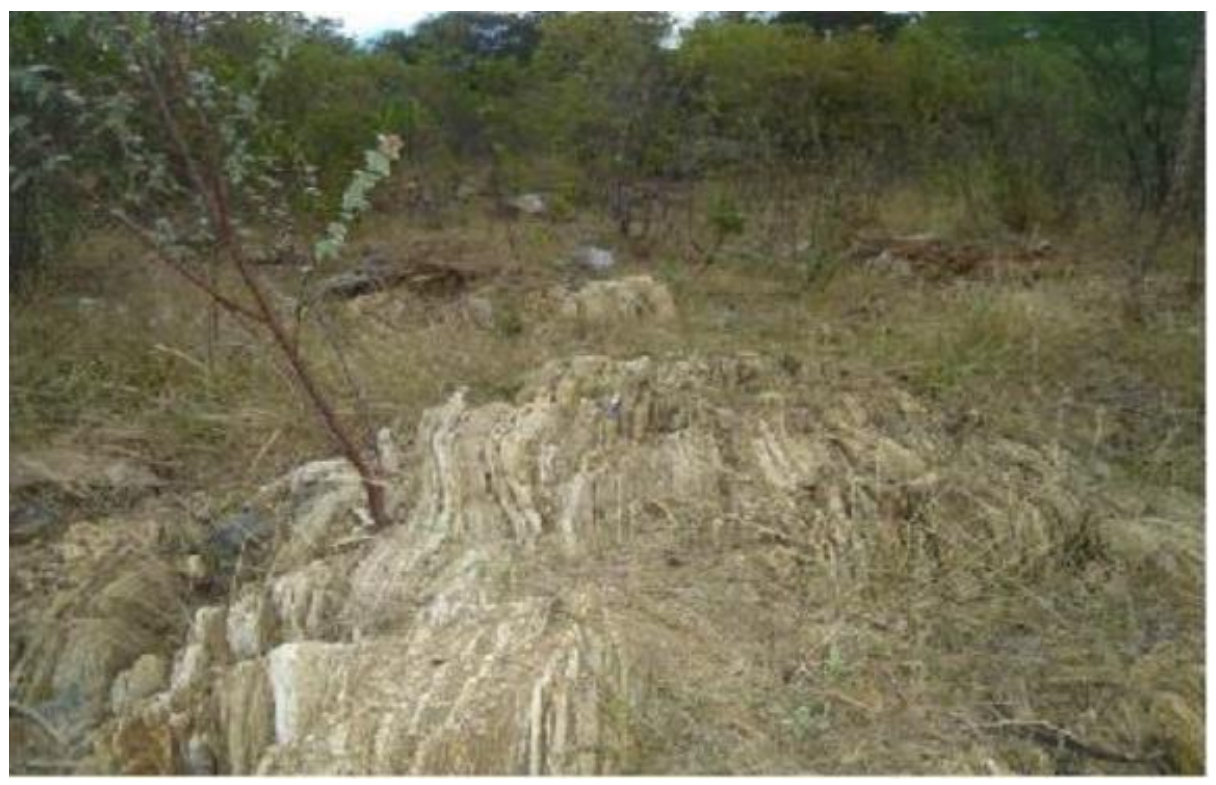

Figura 1 - Embasamento gnáissico, litologia encaixante do dique. 
Os corpos do granito Azul Sucuru são, na realidade, segmentos de diques outrora mais contínuos, que se apresentam em geral com expressão topográfica bem visível nas fotografias aéreas e no campo, marcados pelo empilhamento de matacões (figura 2) com formas e tamanhos variados. Estão direcionados para N-S, com variações para NNE, NNW e NW, mergulhos tendentes à verticalidade e encaixados em litologias dos complexos Sertânia e Sumé, especialmente em gnaisses leucocráticos com anfibolitos associados.

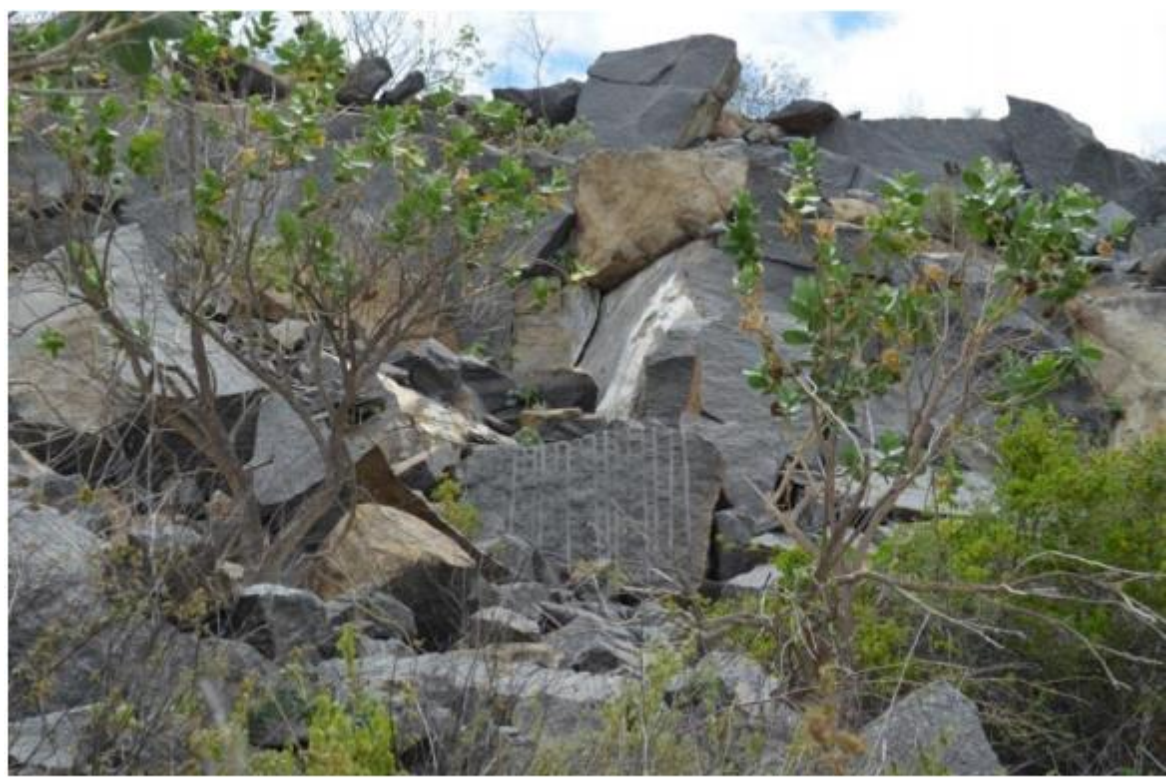

Figura 2 - Matacões em situação de lavra.

Esta rocha foi pesquisada e testada no mercado, com a denominação comercial de Granito Azul Sucuru. Apresenta como elemento diferenciador cristais alongados de quartzo associados com cordierita, proporcionando na chapa polida um arranjo cristalográfico de rara beleza estética. Estas estruturas geológicas possuem comprimento máximo de 1.000 metros e larguras médias, da ordem de 15-20 metros.

\subsection{Difração de Raios-X}

A difração de raios $X$ (DRX) é uma técnica indicada para determinar as fases cristalinas presentes em diversos materiais, dentre eles os minerais. Isso acontece porque os átomos se ordenam em planos cristalinos separados entre si por distâncias da mesma ordem de grandeza dos comprimentos da onda dos raios X. Quando se incide um feixe de raios X em um cristal, o mesmo interage com os átomos presentes, gerando o fenômeno de difração de raios $X$. Ela ocorre segundo a Lei de Bragg, a qual estabelece a relação entre os planos que a originaram (característicos para cada fase cristalina).

Essa técnica representa o fenômeno de interação entre o feixe de raios- $X$ incidente e os elétrons dos átomos componentes de um material, relacionado ao espalhamento coerente. A técnica consiste na incidência da radiação em uma amostra e na detecção dos fótons difratados, que constituem o feixe difratado. Em um material onde os átomos estejam arranjados periodicamente no espaço, característica das estruturas cristalinas, o fenômeno da difração de raios-X ocorre nas direções de espalhamento que satisfazem a Lei de Bragg (equação 1). A teoria da difração é detalhada por Cullity (1967). 
$\mathrm{n} \lambda=2 \mathrm{~d} \operatorname{sen} \theta(1)$

\section{METODOLOGIA}

\subsection{Difração de Raios-X}

Esse estudo fundamenta-se numa análise do pó do material britado do Granito Azul Sucuru. Os ensaios de difração de raios-X foram realizados Laboratório de Tecnologia Mineral da UFPELTM, cujo responsável é o Prof. Dr. Pedro Luiz Guzzo. Busca-se ao longo dessa pesquisa obter difratogramas usando o equipamento Bruker D2 Phaser e detector Bruker-Lynxeye, operando com $300 \mathrm{~W}$ (30 kV e $10 \mathrm{~mA}$ ), irradiação Cu-K $\alpha 1$ ( $\lambda=1,5406 \AA$ ). $2 \theta=4-80^{\circ}$; fenda primária: $0,4 \mathrm{~mm}$; passo do goniômetro: $0,0202 \%$; tempo de contagem por passo: $1 \mathrm{~s}$. As amostras foram preparadas por back-loading.

A partir da DRX possibilita a identificação dos minerais principais (ao passo que a microscopia não foi capaz de identificar alguns minerais, mas sim seus grupos), sendo esse um método que pode ser considerados complementar para a caracterização mineralógica de rochas.

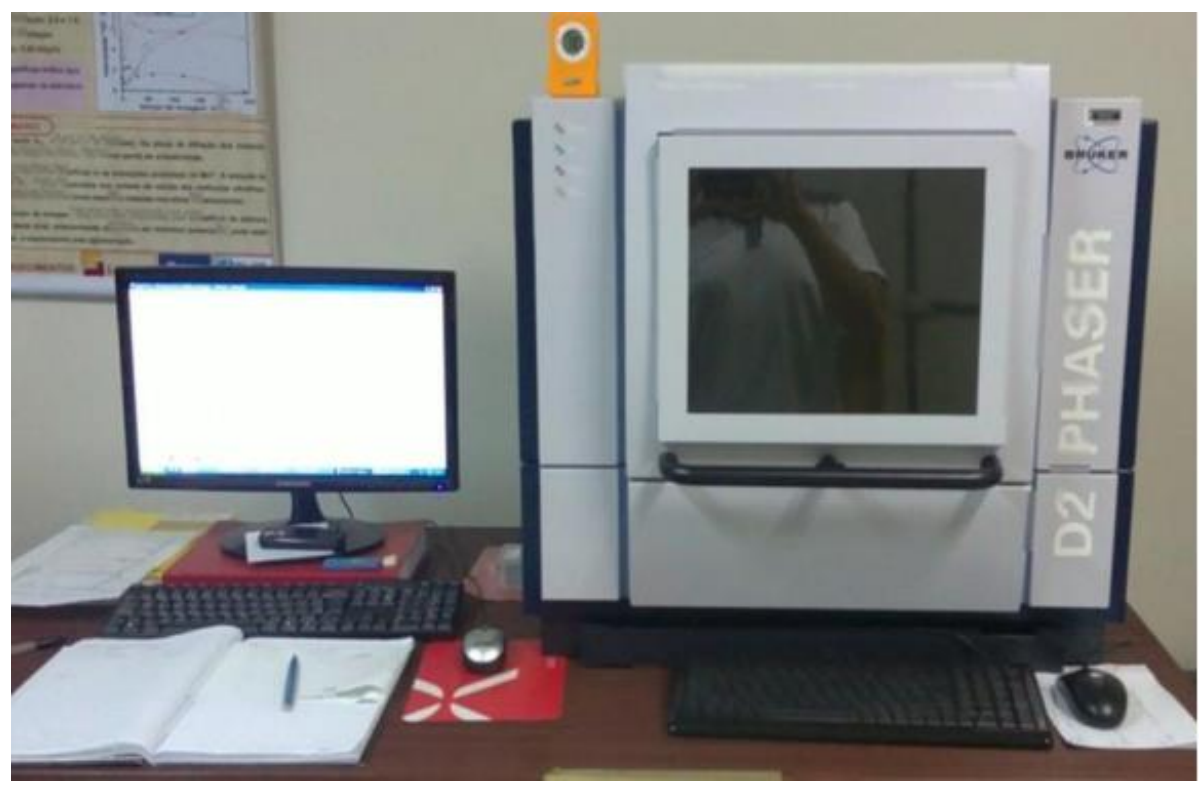

Figura 3: Equipamento utilizado para gerar os difratogramas

\section{DISCUSSÃO E RESULTADOS}

\subsection{Difração de Raios X}

A partir dos resultados dos difratogramas obtidos pela DRX, as análises indicam a existência da cordierita nesse material, a qual potencializa a cor azul da rocha estudada, além dos minerais presentes no pó da brita desse material o que indica aplicações na indústria da construção civil e como rocha ornamental e de revestimento. Assim, comprovam-se os resultados obtidos na análise de petrografia microscópica feita do material amostrado. O estudo dos difratogramas é, no máximo, semiquantitativo, mas confirma o elevado teor de quartzo (25\%) identificado extensivamente nos estudos petrográficos, inclusive microscópicos. Trata-se de mineral essencial 
de dureza bastante elevada (dureza 7,0 na Escala de Mohs) mais abundante na Crosta Terrestre, localizadamente associado com cordierita (5\%), mineral do grupo dos ciclosilicatos, de dureza elevada, mas de frequência mais rara, compondo o grupo dos minerais acessórios da rocha. Assim, esta consorciação de minerais sugere que este é um tipo de rocha que pode ser aplicada em revestimentos internos, externos, áreas secas e úmidas e também em pisos de grande intensidade de pisoteio. Os difratogramas seguintes mostrados nas figuras 4 a 10 ilustram as características difratométricas dos minerais identificados:

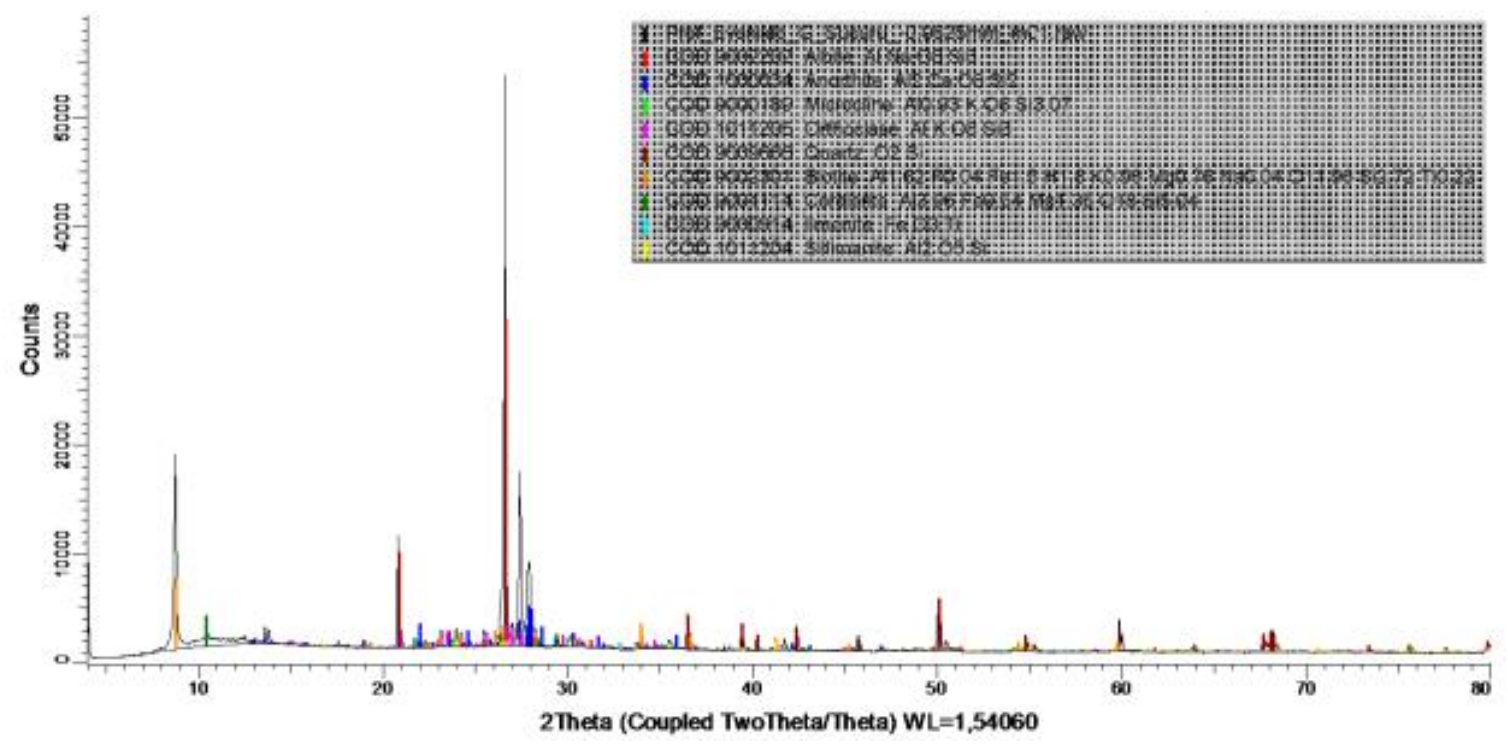

Figura 4: Material passante na peneira $\# 0,625 \mathrm{~mm}$.

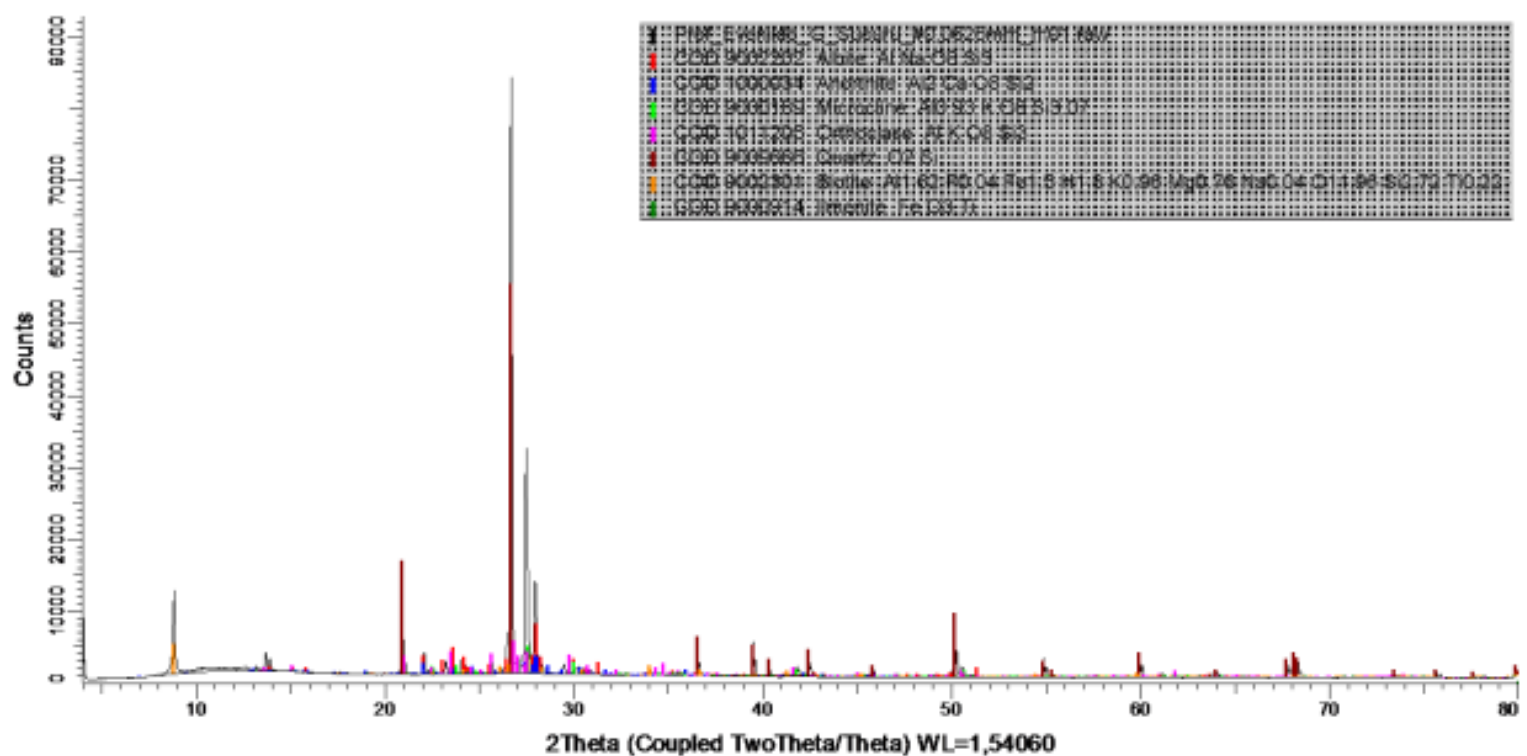

Figura 5: Material passante na peneira $\# 0,625 \mathrm{~mm}$.

As amostras analisadas pela difração de raios $X$ apresentaram mais de uma fase mineral por amostra (de 07 a 09 fases minerais) após a caracterização, por se tratar de materiais rochosos (constituídos por diversas fases minerais, em geral). 


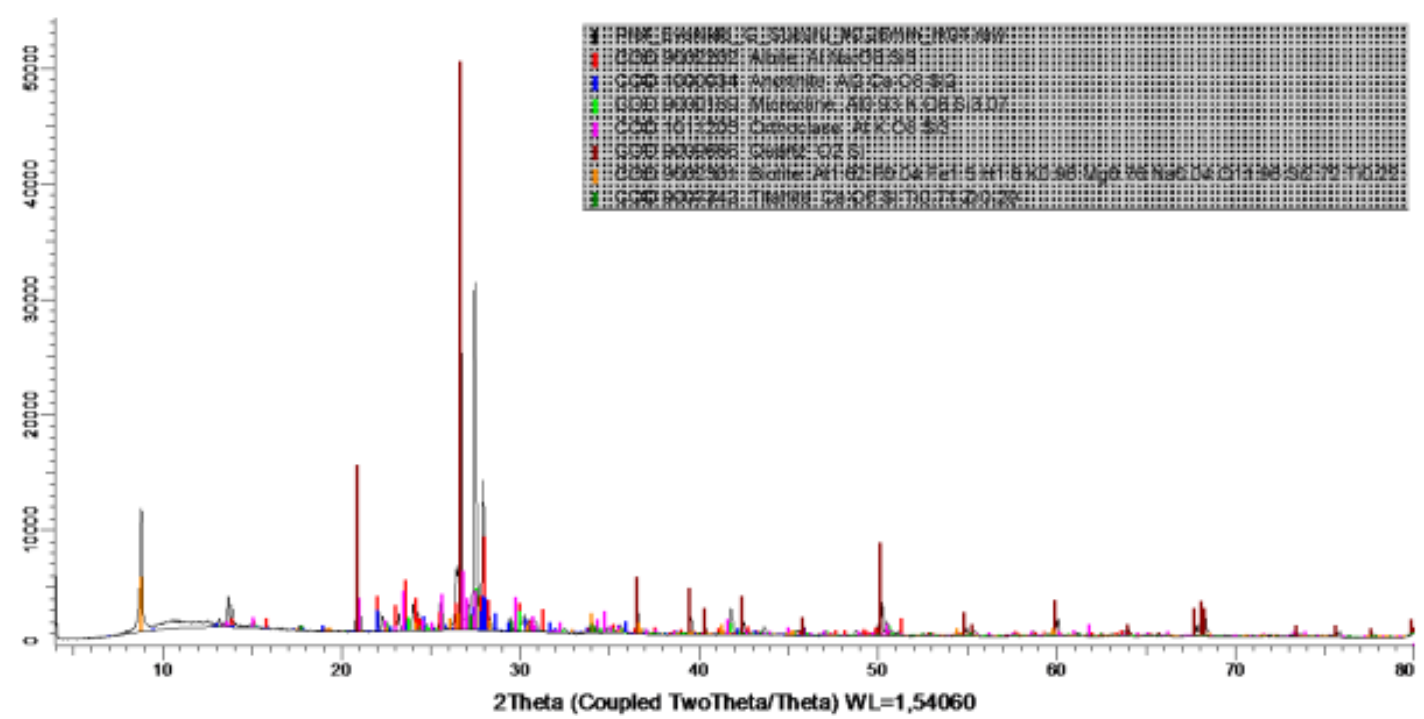

Figura 6: Material retido na peneira \#0,25mm.

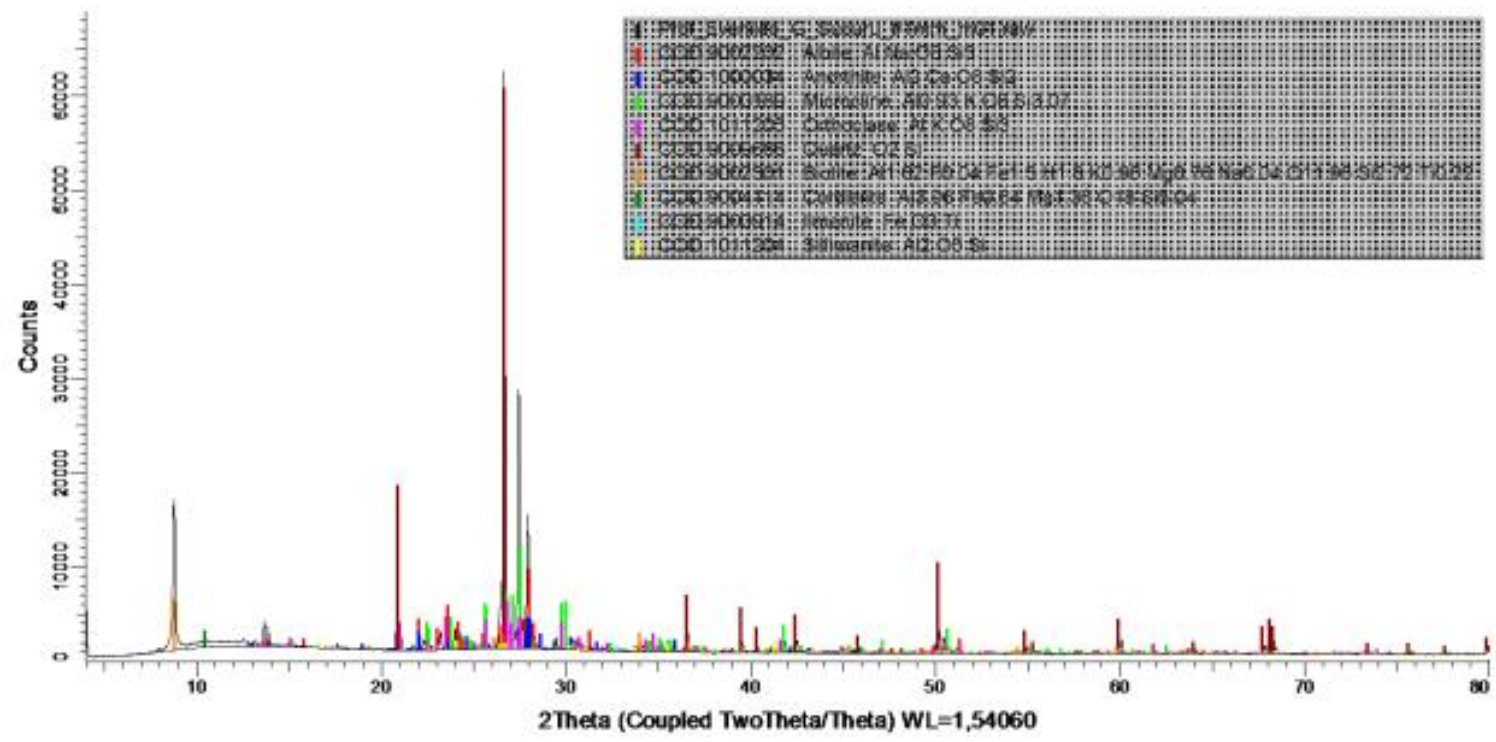

Figura 7: Material retido na peneira \#1,0mm.

Os perfis obtidos por meio de difração de raios $\mathrm{X}$ apresentam características a respeito dos minerais presentes na amostra. Percebe-se a presença de picos de Quartzo por ser o mineral mais abundante na face da Terra apresenta o maior pico em todos os difratogramas acima, além de compor o grupo dos silicatos ocorre comumente em rochas magmáticas, metamórficas e sedimentares., mas aparecem picos de varidades da série dos feldspatos como Albita Microclina, Anortita e Ortoclásio. Ainda se pode perceber a presença de minerais ferromagnesianos, como a biotita, fato que prejudica a aplicação desse material como revestimento externo e sob ação de umidade, mas, o mesmo com aplicações de técnicas impermeabilizantes, pode evitar o problema de oxidação do material devido ao pequeno teor de ferro e maior quantidade de magnésio. 


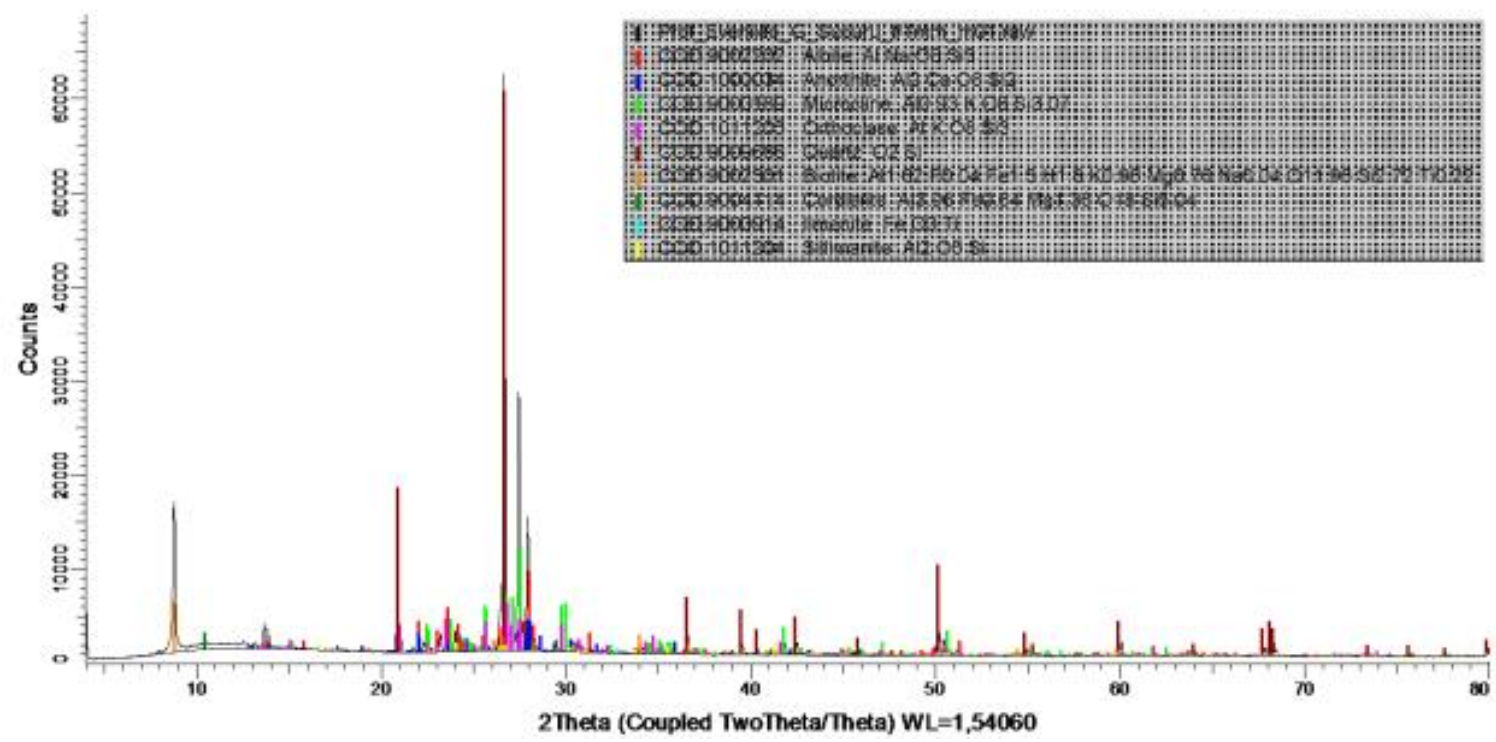

Figura 8: Material retido na peneira \#2,0mm

Os resultados obtidos por meio de difração de raios $\mathrm{X}$ apresentam características a respeito dos minerais presentes na amostra. Ainda se pode perceber a pouca presença de minerais ferromagnesianos, fato que não prejudica a aplicação desse material como revestimento interno ou externo, pois, o problema de oxidação é quase nulo devido ao pequeno teor de ferro e maior quantidade de magnésio.

Portanto, a partir da DRX observa-se que o "Granito Azul Sucuru" apresenta a cor azulada nos cristais de quartzo devido a presença da cordierita como mineral acessório, a qual não apresenta clivagem, logo sua fragmentação é alta, fato que a determina o seu aparecimento em granulometrias mais finas, já o quartzo por ser mais abundante aparece em todos os difratogramas.

Assim, os difratogramas acima, são distintos, não só quanto à cristalinidade, mas, sobretudo quanto às composições das fases, onde são observadas impurezas, provavelmente pela associação com outros minerais, como as micas, cordierita, ilmanita, silimanita e titanita.

\section{CONSIDERAÇÕES FINAIS}

As análises por difração de raios $X$ apresentam como resultados os minerais presentes na rocha, os quais apresentam características intrínsecas do material, além de mostrar a presença de materiais de alteração do litotipo rochoso. Por meio da análise por difração de raios $X$, têm-se informações suficientes para determinar a otimização de uma metodologia para análise petrográfica das características de granitos e possíveis aplicações dos mesmos seja na área ornamental e/ou em outras aplicações na construção civil como agregados na forma de areias e britas. A junção dessas duas técnicas, análise petrográfica e análise por difração de $X$, possibilita um estudo mais detalhado da matéria-prima a ser usada na produção ornamental e na construção civil.

Portanto, o fato primordial que afere a beleza do Granito Azul Sucuru é a presença do mineral Cordierita que aparece como acessório, mas que dá a cor azulada quando associado ao Quartzo. 


\section{REFERÊNCIAS BIBLIOGRÁFICAS}

1. ABIROCHAS. Rochas ornamentais no século XXI. Banco de dados. Disponível na Internet. http://www.abirochas.com.br/br/index.html . Acesso em 25 de janeiro de 2016.

2. CPRM, Programa de Levantamentos Geológicos Básicos do Brasil. 1998.

3. CULLITY, B. D. Elements of X-ray Diffraction, Massachusetts:Addison-Wesley Publishng Company, Inc., 1967. 514p

4. DANA, James D. Manual de Mineralogia, p. $133-154,1981$.

5. LUZ, A.B. et al. Tratamento de Minérios. Rio de Janeiro: CETEM/CNPq, p. 55-75, 1995. 